\title{
Correction to: Association between Firearm Laws and Homicide in Urban Counties
}

\author{
Cassandra K. Crifasi • Molly Merrill-Francis - Alex McCourt • \\ Jon S. Vernick • Garen J. Wintemute • Daniel W. Webster
}

Published online: 16 August 2018

(C) The New York Academy of Medicine 2018

Correction to: Journal of Urban Health (2018) 95(3):383-90. DOI https://doi.org/10.1007/s11524018-0273-3

The authors would like to publish this erratum to correct estimates generated from regression analyses due to errors discovered in the coding of some state laws. The following corrections to the laws in Table 1 are warranted: 1) Michigan no longer requires a permit-to-purchase for handgun sales by licensed dealers effective December 18, 2012 (permits are still necessary for private transfers); 2) Connecticut enacted a law prohibiting firearm purchases for violent misdemeanants effective October 1, 1994; and 3) the implementation dates for violent misdemeanant prohibition laws are January 1, 1996 for Illinois, October 1, 1996 for Maryland, and August 1, 2003 for Minnesota. We regret that we did not identify the errors prior to publication. The data presented below reflect the study's findings after these corrections were made. Changes to the point estimates for the laws' association with homicide rates were minor, and the direction and significance level of the estimates for the effects of the laws studied on firearm

The online version of the original article can be found at https://doi.org/10.1007/s11524-018-0273-3

C. K. Crifasi $(\bowtie) \cdot$ M. Merrill-Francis · A. McCourt •

J. S. Vernick • D. W. Webster

Center for Gun Policy and Research, Bloomberg School of Public Health, Johns Hopkins University, Baltimore, MD, USA

e-mail: crifasi@jhu.edu homicide did not change. The largest change was to the IRR for laws prohibiting firearms for violent misdemeanants' association with firearm homicide rates, which went from 1.14 to 1.24 .

\section{ABSTRACT.}

1. The sentencing beginning "PTP laws were associated with..." should be replaced with a sentence that reads "PTP laws were associated with an $11 \%$ reduction in firearm homicide in large, urban counties (IRR = 0.89, 95\% CI 0.85-0.93)."

\section{RESULTS.}

1. Table 1 should be deleted and replaced with the corrected Table 1 below.

2. Table 2 should be deleted and replaced with the corrected Table 2 below.

3. The second paragraph (describing the regression results in Table 2) should be deleted and replaced with the following: "Table 2 presents the effects of the firearm policies we examined on firearm homicide in large, urban counties after controlling for identified covariates. PTP laws were associated with an $11 \%$ reduction in

G. J. Wintemute

Violence Prevention Research Program, Department of Emergency Medicine, University of California Davis, Sacramento, CA, USA 
Table 1 Firearm Laws and Effective Dates by State.

\begin{tabular}{|c|c|c|c|c|c|}
\hline State (\# of Counties) & $\begin{array}{l}\text { Permit to } \\
\text { Purchase }\end{array}$ & $\begin{array}{l}\text { Comprehensive } \\
\text { Background } \\
\text { Check Only }\end{array}$ & Right to Carry & $\begin{array}{l}\text { Stand Your } \\
\text { Ground }\end{array}$ & $\begin{array}{l}\text { Violent } \\
\text { Misdemeanor } \\
\text { Restriction }\end{array}$ \\
\hline Alabama (1) & & & pre-1984 & $6 / 1 / 06$ & \\
\hline Arizona (1) & & & 4/13/94 & $4 / 24 / 06$ & \\
\hline California (12) & & $1 / 1 / 91$ & & & $1 / 1 / 91$ \\
\hline Colorado (4) & & $7 / 1 / 13$ & $5 / 17 / 03$ & & \\
\hline Connecticut (1) & $10 / 1 / 95$ & & & & $10 / 1 / 94$ \\
\hline Delaware (1) & & $7 / 1 / 13$ & & & \\
\hline Florida (9) & & & $10 / 1 / 87$ & $10 / 1 / 05$ & \\
\hline Georgia (4) & & & $8 / 25 / 89$ & 7/1/06 & \\
\hline Illinois (7) & pre-1984 & & $1 / 5 / 14$ & & $1 / 1 / 96$ \\
\hline Indiana (2) & & pre-1984-11/30/98 & pre-1984 & $7 / 1 / 06$ & \\
\hline Kansas (1) & & & $1 / 1 / 07$ & $5 / 26 / 06$ & \\
\hline Kentucky (1) & & & $10 / 1 / 96$ & $7 / 12 / 06$ & \\
\hline Louisiana (2) & & & $4 / 19 / 96$ & $8 / 1 / 06$ & \\
\hline Maryland (5) & $10 / 1 / 13$ & $10 / 1 / 96-10 / 1 / 13$ & & & $10 / 1 / 96$ \\
\hline Massachusetts (6) & pre-1984 & & & & \\
\hline Michigan (4) & pre-1984-12/18/12 & & $7 / 1 / 01$ & $10 / 1 / 06$ & \\
\hline Minnesota (4) & & & $5 / 28 / 03$ & & $8 / 1 / 03$ \\
\hline Missouri (3) & pre-1984-8/28/07 & & $2 / 26 / 04$ & $8 / 28 / 07$ & \\
\hline Nevada (1) & & & $10 / 1 / 95$ & $10 / 1 / 11$ & \\
\hline New Hampshire (1) & & & pre-1984 & $11 / 13 / 11$ & \\
\hline New Jersey (13) & pre-1984 & & & & \\
\hline New York (14) & pre-1984 & & & & pre-1984 \\
\hline North Carolina (2) & pre-1984 & & $12 / 1 / 95$ & $12 / 1 / 11$ & \\
\hline Ohio (6) & & & $4 / 8 / 04$ & & \\
\hline Oklahoma (1) & & & $1 / 1 / 96$ & $11 / 1 / 06$ & \\
\hline Oregon (3) & & $8 / 9 / 2015$ & $1 / 1 / 90$ & & \\
\hline Pennsylvania (8) & & $10 / 11 / 95$ & $6 / 17 / 89$ & $8 / 29 / 11$ & \\
\hline Rhode Island (1) & & pre-1984 & pre-1984 & & \\
\hline Tennessee (2) & & $5 / 10 / 94-11 / 1 / 98$ & $10 / 1 / 96$ & $5 / 22 / 07$ & \\
\hline Texas (6) & & & $1 / 1 / 96$ & $9 / 1 / 07$ & \\
\hline Utah (1) & & & $5 / 1 / 95$ & $3 / 1 / 94$ & \\
\hline Virginia (3) & & & $5 / 5 / 95$ & & \\
\hline Washington (4) & & $12 / 4 / 14$ & pre-1984 & & \\
\hline Wisconsin (2) & & & $11 / 1 / 11$ & & \\
\hline $\begin{array}{l}\text { Total states with law during study period } \\
\text { (total \# of changes) }\end{array}$ & $9(3)$ & $10(9)$ & $27(22)$ & $18(18)$ & $6(5)$ \\
\hline
\end{tabular}

firearm homicide $(\mathrm{IRR}=0.89,95 \%$ CI $0.85-0.93)$. CBC-only laws were associated with a $10 \%$ increase in firearm homicide (IRR $=1.10,95 \%$ CI $1.08-1.13$ ). RTC laws were associated with a $7 \%$ increase in firearm homicide $($ IRR $=1.07,95 \%$ CI 1.05-1.09). SYG laws were associated with an $8 \%$ increase in firearm homicide $($ IRR $=1.08,95 \%$ CI $1.05-1.10)$. VM laws were associated with a $24 \%$ increase in firearm homicide $(\operatorname{IRR}=1.24,95 \%$ CI $1.21-1.27)$. When we included the proxy for county-level firearm ownership, there 
Table 2 Effects of Firearm Laws on Firearm Homicide in Large, Urban U.S. Counties, 1984-2015.

\begin{tabular}{lll}
\hline & IRR $^{\mathrm{a}}$ & 95\% CI \\
\hline Permit to Purchase & 0.89 & $0.85-0.93$ \\
Comprehensive Background Check only & 1.10 & $1.08-1.13$ \\
Right to Carry & 1.07 & $1.05-1.09$ \\
Stand Your Ground & 1.08 & $1.05-1.10$ \\
Violent Misdemeanor prohibitions & 1.24 & $1.21-1.27$ \\
County-level \% Population African American & 1.55 & $1.51-1.60$ \\
$\quad$ Male Youth & 1.00 & $1.00-1.00$ \\
County-level Poverty Rate & 1.00 & $1.00-1.01$ \\
County-level Unemployment Rate & 1.00 & $1.00-1.00$ \\
State-level Incarceration Rate & 0.99 & $0.99-0.99$ \\
State-level Law Enforcement Expenditures & & \\
a Incidence Rate Ratio & & \\
b 95\% Confidence Interval & & \\
Note: The model also included year fixed effects & \\
\hline
\end{tabular}

were negligible differences in the point estimates; however, the firearm ownership proxy itself was associated with a $40 \%$ increase in firearm homicide (IRR $=1.40$, 95\% CI 1.29-1.53)."

4. Figure 1 should be deleted and replaced with the corrected Fig. 1 below.

5. Figure 2 should be deleted and replaced with the corrected Fig. 2 below.

6. Table 3 should be deleted and replaced with the corrected Table 3 below.

7. The last paragraph (presenting results of Table 3) should be deleted and replaced with the following: "Table 3 presents the effects of the same set of firearm policies on non-firearm homicide rates. PTP and SYG were not associated with statistically significant changes in non-firearm homicide. CBC-only laws were associated with a $6 \%$ decrease in non-firearm homicide (IRR $=0.94,95 \%$ CI $0.91-0.98)$. RTC laws were associated with a
Fig. 1 Effects of CBC-only laws on firearm homicide 1, 2, and 3 years pre- and post-enactment.
Fig. 2 Effects of VM laws on firearm homicide 1, 2, and 3 years pre- and post-enactment.
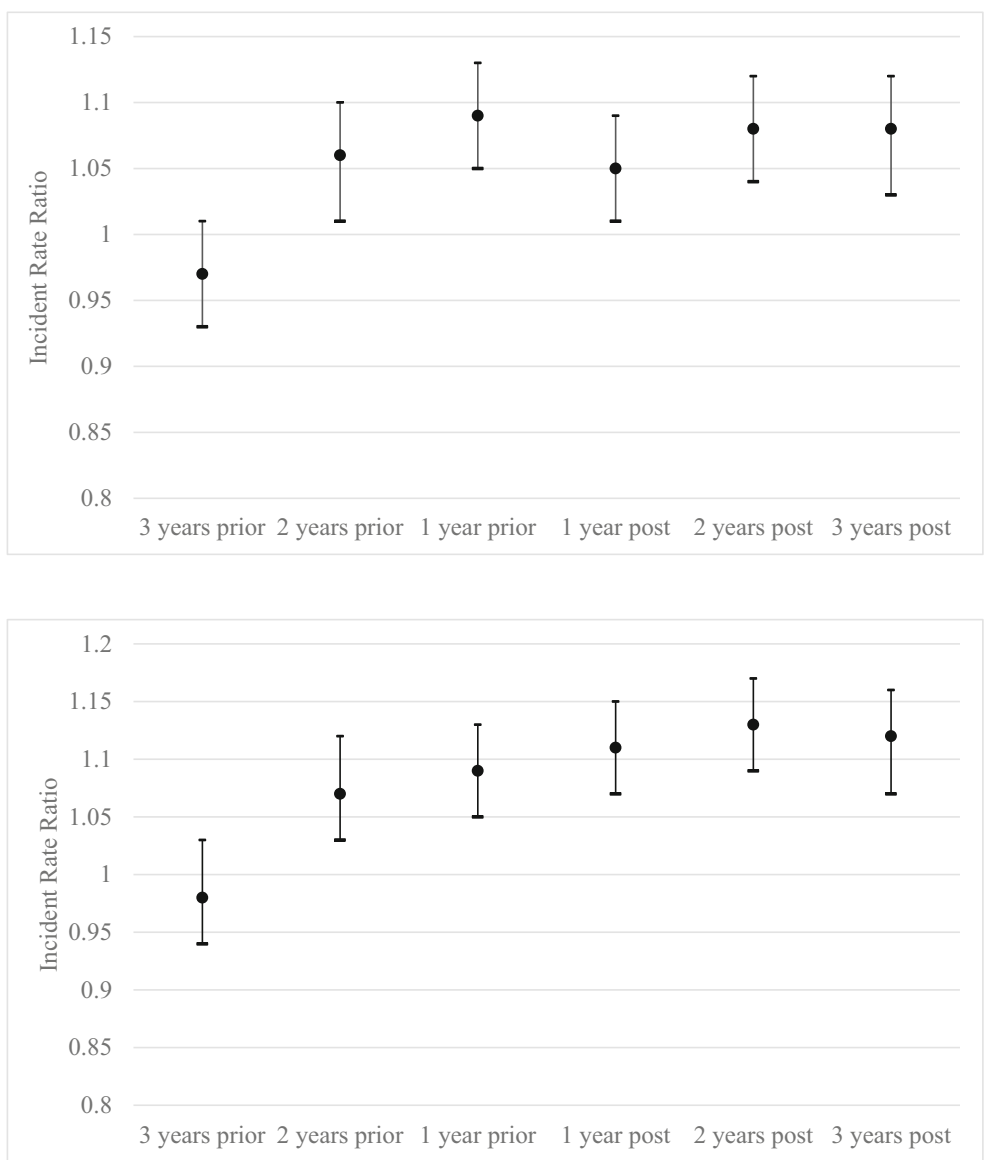
Table 3 Effects of Firearm Laws on Non-Firearm Homicide in Large, Urban U.S. Counties, 1984-2015.

\begin{tabular}{lcc}
\hline & IRR $^{\mathrm{a}}$ & $95 \% \mathrm{Cl}^{\mathrm{b}}$ \\
\hline Permit to Purchase & 1.02 & $0.95-1.09$ \\
Comprehensive Background Check only & 0.94 & $0.91-0.99$ \\
Right to Carry law & 1.04 & $1.01-1.07$ \\
Stand Your Ground & 1.01 & $0.98-1.05$ \\
Violent Misdemeanor prohibitions & 1.04 & $1.00-1.08$ \\
County-level \% Population African American & 1.53 & $1.48-1.59$ \\
$\quad$ Male Youth & 1.01 & $1.00-1.02$ \\
County-level Poverty Rate & 0.99 & $0.99-1.00$ \\
County-level Unemployment Rate & 1.00 & $1.00-1.00$ \\
State-level Incarceration Rate & 1.00 & $1.00-1.00$ \\
State-level Law Enforcement Expenditures & &
\end{tabular}

${ }^{\mathrm{a}}$ Incidence Rate Ratio

b $95 \%$ Confidence Interval

Note: The model also included year fixed effects
$4 \%$ increase in non-firearm homicide (IRR $=1.04$, 95\% CI 1.01-1.07). When we included the proxy for county-level firearm ownership, there were negligible differences in the point estimates; however, the firearm ownership proxy itself was associated with a $17 \%$ reduction in non-firearm homicide $($ IRR $=0.83$, 95\% CI $0.73-0.93)$.”

DISCUSSION.

1. The second sentence of the third paragraph should be deleted and replaced with the following: "Counties in states with RTC laws experienced a $7 \%$ increase in firearm homicide relative to counties in states with more restrictions on the issuance of concealed carry weapons permits."

2. The second sentence of the fourth paragraph should be deleted and replaced with the following: "Counties in states with SYG laws experienced an $8 \%$ increase in firearm homicide." 